\title{
Efeitos de extratos vegetais e antimicrobianos sobre a digestibilidade aparente, o desempenho, a morfometria dos órgãos e a histologia intestinal de leitões recém-desmamados ${ }^{1}$
}

\section{Liliana Lotufo Oetting ${ }^{2}$, Carlos Eduardo Utiyama², Pedro Agostinho Giani ${ }^{3}$, Urbano dos Santos Ruiz ${ }^{3}$, Valdomiro Shigueru Miyada ${ }^{4}$}

\author{
1 Pesquisa financiada pela FAPESP. \\ 2 Programa de Pós-graduação em Ciência Animal e Pastagens - Depto. de Zootecnia, ESALQ/USP, CEP: 13418-900, Piracicaba/SP. \\ 3 Iniciação Cientifica, Depto. de Zootecnia da ESALQ/USP, Piracicaba/SP. \\ ${ }^{4}$ Departamento de Zootecnia, ESALQ/USP, CEP: 13418-900, Piracicaba/SP.
}

RESUMO - Objetivou-se com este trabalho avaliar o efeito de antimicrobianos e extratos vegetais sobre a digestibilidade, o desempenho, a morfometria e a histologia de leitões recém-desmamados. Foram realizados três experimentos de 35 dias (repetições no tempo), com um total de 120 leitões (40 leitões por experimento). O delineamento foi em blocos casualizados, com cinco tratamentos (controle - ração basal; antimicrobiano - ração basal com bacitracina de zinco, olaquindox e colistina (50 ppm de cada); extrato vegetal A, B e C - ração basal com 700, 1.400 e 2.100 ppm de extrato vegetal, respectivamente), 12 repetições por tratamento e dois animais por unidade experimental. O extrato vegetal continha óleo essencial de cravo, tomilho e orégano, acrescido de eugenol e carvacrol. A digestibilidade foi determinada em 40 leitões (quatro repetições por tratamento) utilizando-se o método de coleta parcial de fezes e o óxido de cromo como marcador. Ao final do primeiro experimento, foi abatido um animal de cada baia para coleta das amostras. A digestibilidade da MS no tratamento com extratos vegetais foi maior que nos tratamentos controle e com antimicrobianos. O tratamento antimicrobiano promoveu os melhores resultados de desempenho em todos períodos analisados. O maior nível de inclusão de extratos vegetais foi o que proporcionou os melhores resultados de desempenho e das demais variáveis. O tratamento com antimicrobianos resultou em menor peso relativo do trato gastrintestinal total e do intestino delgado vazio, além de maior altura de vilosidade e menor relação altura de vilosidade x profundidade de cripta do íleo que os tratamentos com extratos vegetais. Entretanto, são necessários mais estudos sobre os óleos essenciais a serem utilizados, a concentração de cada óleo, a melhor combinação e o melhor nível de inclusão na dieta.

Palavras-chave: aditivos, extratos herbais, promotores do crescimento, suínos

\section{Effects of herbal extracts and antimicrobials on apparent digestibility, performance, organs morphometry and intestinal histology of weanling pigs}

\begin{abstract}
The purpose of this trial was to evaluate the effects of antimicrobial and herbal extracts on digestibility, performance, morphology and histology of weanling pigs. One hundred and twenty weaned pigs were used to compare five treatments: control - basal diet; antimicrobial - basal diet plus Zn bacitracina, olaquindox, and colistin (50 ppm of each); herbal extract A, B and C - basal diet plus $700 \mathrm{ppm}, 1,400 \mathrm{ppm}$ and 2,100 ppm of herbal extract, respectively, with 12 replications (pens of two pigs each) per treatment in a 35-d randomized complete block design experiment. The herbal extract consisted of mixture of equal amounts of essential oils of thyme, clove, oregano, eugenol and carvacrol. In digestibility assay, 40 pigs (four replications per treatment) were fed a diet with chromium oxide (marker method). On $35^{\text {th }}$ day of experimental period, one animal of each experimental unit was slaughtered and samples were collected for analysis. The herbal extracts increased dietary DM apparent digestibility compared to control and antimicrobial treatments. The antimicrobial agents improved performance of weanling pigs during all phases of the experimental period compared to the other treatments. Pigs fed high dietary level of herbal extract showed better results for pig performance and other variables. The antimicrobial treatment improved the relative weights of intestinal tract and empty small intestine and improved ileum villus height and ileum villus height:crypt depth ratio of animals. However, more studies are necessary to evaluate which type of essential oil should be used and the best combination and inclusion level of herbal extract in the diet.
\end{abstract}

Key Words: additives, growth promoters, herbal extract, swine 


\section{Introdução}

A demanda de alimentos para atender às necessidades da população mundial requer produção intensiva de proteína de origem animal e das demais fontes de nutrientes, respeitando cada vez mais as questões sociais, de meio ambiente e segurança alimentar. Os aditivos antimicrobianos (antibióticos e quimioterápicos) têm sido utilizados desde a década de 50 e são os promotores do crescimento de uso mais generalizado na produção animal (Menten, 2002). Apesar da comprovada capacidade de melhorar o desempenho de suínos, o uso de antimicrobianos como promotores do crescimento vem sendo progressivamente restringido, pois existe a possibilidade de desenvolvimento da resistência bacteriana cruzada em humanos e à emergente exigência dos importadores por produtos livres de resíduos de antibióticos (Silva, 2000). Essas novas regulamentações têm forçado a procura por alternativas que garantam o máximo crescimento dos animais sem afetar a qualidade do produto final(Miltenberg, 2000).

A utilização de extratos vegetais e plantas medicinais para humanos data de milhares de anos, sendo muito difundida no Egito Antigo, na China, na Índia e na Grécia (Kamel, 2000). Os principais efeitos pesquisados em experimentos in vitro incluem o efeito antimicrobiano e antioxidante dos extratos herbais. Os efeitos exercidos pelas plantas podem ser explicados pela presença e constituição de seu(s) princípio(s) ativo(s). Na formulação de rações, recomenda-se a utilização de uma combinação de diferentes extratos herbais, reforçados com seus princípios ativos, para atingir resultados técnicos satisfatórios (Brugalli, 2003). No entanto, ainda não foi esclarecido se uma ação particular, como antioxidante, antimicrobiana, imunomoduladora, etc. pode estar associada a uma molécula específica e/ou alguma substância ativa presente na planta, que pode ter múltiplas funções (Brugalli, 2003).

Entre os possíveis mecanismos de ação dos extratos vegetais no organismo animal, podemos citar estimulação da digestão, alterações na microbiota intestinal, aumento na digestibilidade e absorção de nutrientes e efeitos antimicrobiano e imunomodulador (Mellor, 2000). Apesar da comprovada ação in vitro de diversos extratos herbais, existem poucas informações sobre seu uso em suínos.

Objetivou-se com este estudo avaliar o efeito de níveis crescentes da combinação de extratos vegetais e antimicrobianos sobre o desempenho, a digestibilidade dos nutrientes, a morfometria dos órgãos e a histologia do epitélio intestinal de leitões recém-desmamados.

\section{Material e Métodos}

Foram utilizados 120 suínos híbridos, no período de 21 a 56 dias de idade, distribuídos em um delineamento em blocos casualizados, com cinco tratamentos, 12 repetições por tratamento e dois animais por unidade experimental (um macho castrado e uma fêmea). Como a creche experimental possuía apenas 20 baias, realizaram-se três experimentos separados (repetições no tempo) com 40 animais e quatro blocos por repetição no tempo.

Os tratamentos consistiram de: controle - ração basal (C); antimicrobiano - ração basal com bacitracina de zinco, olaquindox e colistina (50 ppm de cada) (A); extrato vegetal A, B e C - ração basal com 700 (Ea), 1.400 (Eb) e 2.100 (Ec) ppm de extrato vegetal, respectivamente.

O extrato vegetal foi constituído de óleo essencial de cravo, tomilho e orégano, acrescido dos princípios ativos eugenol e carvacrol. Os extratos passaram por um processo de microencapsulamento com o objetivo de minimizar o sabor dos óleos na dieta e liberá-los mais lentamente no estômago do animal. A composição final do produto encapsulado consistiu de $20 \%$ da mistura dos óleos, sendo $3,33 \%$ de óleo essencial de cravo, 3,33\% de eugenol (princípio ativo do cravo), 3,33\% de óleo essencial de orégano, $3,33 \%$ de carvacrol (princípio ativo do orégano) e $6,66 \%$ de óleo essencial de tomilho.

Foram utilizadas duas rações basais durante o período experimental: pré-inicial ( $1^{\circ}$ ao $14^{\circ}$ dia de experimento) e inicial ( $15^{\circ}$ ao $35^{\circ}$ dia). As composições percentuais das rações basais, assim como os valores calculados de alguns nutrientes, encontram-se na Tabela 1.

Para determinação da digestibilidade aparente, 40 leitões do primeiro experimento (primeira repetição no tempo), receberam as respectivas rações experimentais acrescidas de $0,05 \%$ de óxido de cromo. Utilizou-se o método da coleta parcial de fezes, sendo a ração marcada fornecida a partir do $22^{\circ}$ dia de experimentação. A coleta de fezes foi realizada durante quatro dias (manhã e tarde), com início no $28 \underline{0}$ dia de experimentação.

Durante o período experimental, os animais receberam água e ração à vontade. As variáveis de desempenho (consumo diário de ração, ganho de peso diário e conversão alimentar) foram calculadas por meio da pesagem dos animais e quantificações das rações, feitas periodicamente.

Ao final do primeiro experimento, foi abatido um animal por unidade experimental para coleta dos dados e amostragem para estudo da morfometria e análise da histologia dos órgãos. O animal abatido foi escolhido de 
Tabela 1 - Composições centesimal e nutricional das dietas basais

Table 1 - Ingredient and calculated compositions of the basal diets

\begin{tabular}{|c|c|c|}
\hline $\begin{array}{l}\text { Ingrediente, \% } \\
\text { Ingredient }\end{array}$ & $\begin{array}{l}\text { Pré-inicial } \\
\text { Pre-Initial }\end{array}$ & $\begin{array}{l}\text { Inicial } \\
\text { Initial }\end{array}$ \\
\hline Milho (Corn) & 59,269 & 63,329 \\
\hline Farelo de soja $46 \%$ (Soybean meal) & 15,171 & 23,500 \\
\hline Produto lácteo $40 \%{ }^{1}$ (Milk product) & 10,532 & 2,673 \\
\hline Lactose (Lactose) & 6,000 & 2,992 \\
\hline Plasma sangüíneo ${ }^{2}$ (Plasma) & 4,300 & 2,000 \\
\hline Fosfato bicálcico (Dicalcium phosphate) & 1,227 & 1,497 \\
\hline Calcário (Limestone) & 1,095 & 1,024 \\
\hline Óleo de soja (Soybean oil) & 0,800 & 1,500 \\
\hline L-lisina. $\mathrm{HCl} 78 \%$ (L-lysine) & 0,577 & 0,427 \\
\hline L-treonina $98,5 \%$ (L-threonine) & 0,224 & 0,162 \\
\hline DL-metionina $99 \%$ (DL-methionine) & 0,215 & 0,145 \\
\hline L-triptofano $98 \%$ (L-tryptophan) & 0,081 & 0,016 \\
\hline Cloreto de colina $60 \%$ (Choline chloride) & 0,100 & 0,100 \\
\hline Premix mineral (Mineral premix) $)^{3}$ & 0,100 & 0,100 \\
\hline Premix vitamínico (Vitamin premix) ${ }^{4}$ & 0,100 & 0,100 \\
\hline Sal (Salt) & 0,000 & 0,225 \\
\hline $\begin{array}{l}\text { Inerte e/ou promotor do crescimento } \\
\text { Inert and/or growth promoter }\end{array}$ & 0,210 & 0,210 \\
\hline
\end{tabular}

Valores calculados, \%

Calculated values

\begin{tabular}{lrr}
\hline Energia metabolizável, kcal/kg & 3.400 & 3.300 \\
Metabolizable energy & & \\
Proteína bruta (Crude protein) & 20,00 & 19,50 \\
Lisina total (Total lysine) & 1,50 & 1,33 \\
Lisina digestível (Digestible lysine) & 1,34 & 1,19 \\
Treonina digestível (Digestible threonine) & 0,86 & 0,77 \\
Triptofano digestível (Digestible tryptophan) & 0,27 & 0,21 \\
Metionina digestível (Digestible methionine) & 0,46 & 0,39 \\
Metionina + cistina digestíveis & 0,79 & 0,69 \\
Digestible Met + Cys & & \\
Lactose (Lactose) & 11,76 & 4,00 \\
Cálcio (Calcium) & 0,85 & 0,87 \\
P disponível (Available P) & 0,45 & 0,42 \\
\hline
\end{tabular}

1 Produto comercial (comercial product): Nuklospray K-10.

${ }^{2}$ Produto comercial (comercial product): AP920.

${ }^{3}$ Quantidades supridas por $\mathrm{kg}$ de ração (supplemented amounts per kg of diet): vit. $\mathrm{A}, 6.000 \mathrm{UI}$; vit. $\mathrm{D}_{3}, 1.500 \mathrm{Ul}$; vit. E, $15 \mathrm{Ul}$; vit. $\mathrm{K}_{3}, 1,5 \mathrm{mg}$; tiamina (thiamin), $1,35 \mathrm{mg}$; riboflavina (riboflavin), $4 \mathrm{mg}$; vit. piridoxina (pyridoxine), $2 \mathrm{mg}$; vit. $\mathrm{B}_{12}, 0,02 \mathrm{mg}$; ácido nicotínico (nicotinic acid), $20 \mathrm{mg}$; ácido fólico (folic acid), $0,6 \mathrm{mg}$; biotina (biotin), $0,8 \mathrm{mg}$; ácido pantotênico (pantothenic acid), $9,35 \mathrm{mg}$; selênio (selenium) $0,3 \mathrm{mg}$.

${ }^{4}$ Quantidades supridas por kg de ração (supplemented amounts per kg of diet): I, $1,5 \mathrm{mg}$; Co, $1 \mathrm{mg} ; \mathrm{Cu}, 10 \mathrm{mg} ; \mathrm{Zn}, 100 \mathrm{mg}$ Fe, $100 \mathrm{mg}$; Mg, $40 \mathrm{mg}$

acordo com o peso vivo e apresentava o peso mais próximo da média dos demais.

Imediatamente após o abate e antes da lavagem do intestino delgado, foram coletados segmentos de cerca de $5 \mathrm{~cm}$ de comprimento do duodeno $(15 \mathrm{~cm}$ do esfíncter estomacal), jejuno (1,5 m da junção do íleo com o intestino grosso) e íleo (20 cm da junção com o intestino grosso). As amostras foram abertas ao longo do mesentério, fixadas em papelão com grampos e acondicionadas em líquido fixador de Bouin. Posteriormente, foram encaminhadas ao laboratório para processamento e posterior análise histológica.

Dos animais abatidos, foram retirados e pesados os órgãos digestivos (trato gastrintestinal total, estômago vazio, intestino delgado vazio, pâncreas, fígado, vesícula biliar, intestino grosso vazio, ceco vazio e colo vazio) e os não digestivos (baço, rins, pulmões e coração). Também foi feita a medição do comprimento do intestino delgado dos animais.

Os dados das variáveis de digestibilidade e histologia foram analisados considerando quatro repetições por tratamento, com dois animais por unidade experimental. Para análise dos dados de morfometria, foram consideradas oito repetições por tratamento, pois, no segundo experimento (repetição no tempo), os animais também foram abatidos para pesagem dos órgãos.

Os dados foram analisados pelo SAS LAB para verificação da adequação dos dados ao modelo linear. Posteriormente, foi feita análise de variância pelo PROC GLM (General Linear Models) do SAS (SAS, 2001). Os dados de ganho diário de peso e consumo diário de ração também foram submetidos à análise multivariada.

A comparação de médias foi feita por contrastes de interesse. Também foi realizada análise de polinômios ortogonais para os níveis crescentes dos extratos vegetais na dieta, incluindo o tratamento controle na análise.

\section{Resultados e Discussão}

Constam na Tabela 2 as médias dos coeficientes de digestibilidade aparente da matéria seca e energia bruta de acordo com os tratamentos.

A inclusão de níveis crescentes de extrato vegetal na dieta promoveu o aumento $(\mathrm{P}<0,05)$ da digestibilidade aparente da matéria seca em relação aos tratamentos controle e antimicrobiano. Estes resultados estão de acordo com os obtidos por Hernández et al. (2004), em um estudo com frangos no qual foi observado aumento no coeficiente de digestibilidade da MS em relação ao tratamento controle, quando da suplementação da dieta com extratos vegetais à base de orégano, canela e pimenta (T1) e sálvia, tomilho e alecrim (T2), sendo encontradas diferenças significativas para as fases inicial (70,32 vs 71,40 para T1 e 74,49\% para T2) e terminação (63,55 vs 72,20 para T1 e 69,36\% para T2). Entretanto, diferentemente dos resultados apresentados, em outro trabalho (Lee et al., 2003a) não foi observado efeito significativo de extratos vegetais sobre a digestibilidade dos nutrientes em frangos de corte. De acordo com os autores, não houve efeito talvez porque a dieta utilizada era altamente digestível e um aumento na digestibilidade dos nutrientes seria praticamente impossível ou dificilmente detectado.

De acordo com a literatura, a adição de extratos vegetais na dieta pode aumentar a secreção de saliva, suco gástrico, suco pancreático, sais biliares e enzimas do intestino delgado 
Tabela 2 - Médias dos coeficientes de digestibilidade aparente da matéria seca e energia bruta, de acordo com os tratamentos

Table 2 - $\quad$ Average apparent digestibility coefficients of dry matter and crude energy according to treatments

Tratamento $^{1} \quad$ Coeficiente de digestibilidade aparente $(\%)$

Treatment Apparent digestibility coefficient (\%)

\begin{tabular}{lcc}
\cline { 2 - 3 } & $\begin{array}{c}\text { Matéria seca } \\
\text { Dry matter }\end{array}$ & $\begin{array}{c}\text { Energia bruta } \\
\text { Crude energy }\end{array}$ \\
\hline $\mathrm{C}$ & 73,02 & 73,47 \\
$\mathrm{~A}$ & 73,05 & 72,61 \\
$\mathrm{Ea}$ & 72,87 & 72,39 \\
$\mathrm{~Eb}$ & 75,60 & 73,76 \\
$\mathrm{Ec}$ & 76,81 & 75,79 \\
$\mathrm{Pr}>\mathrm{F}$ & 0,0057 & 0,1165 \\
$\mathrm{CV}^{4}(\%)$ & 1,95 & 2,41
\end{tabular}

${ }^{1} \mathrm{C}=$ controle (control); $\mathrm{A}=$ antimicrobiano (antimicrobial); Ea, Eb e Ec $=700$, 1400, 2100 ppm de extrato vegetal (herbal extract), respectivamente.

${ }^{2}$ Contrastes significativos: controle $x$ extratos e antimicrobiano $x$ extratos

2 Significantly different contrasts: control $x$ herbal extract and antimicrobial $x$ herbal extract.

${ }^{3}$ Efeito linear $(P<0,05)$ para os níveis crescentes de extrato na dieta, em que $\hat{\mathrm{Y}}=1,409 \mathrm{x}+71,055\left(\mathrm{R}^{2}=0,875\right)$

${ }^{3}$ Linear effect for increasing levels of herbal extract.

${ }^{4}$ Coeficiente de variação (coefficient of variation).

em ratos (Sambaiah \& Srinivasan, 1991; Platel \& Srinivasan, 1996; Wang \& Bourne, 1998). A presença dessas substâncias na dieta proporciona aumento na produção de pepsina e ácido gástrico pelo organismo e contribui para a redução do $\mathrm{pH}$ estomacal e do intestino delgado, estimulando a secreção pancreática (Mellor, 2000). Essa pode ser uma das explicações para o tratamento com extrato vegetal ter acarretado melhora na digestibilidade aparente da matéria seca.

Os resultados de peso vivo, consumo diário de ração, ganho diário de peso e conversão alimentar nas fases de 1 a 14 e 1 a 35 dias de experimentação encontram-se nas Tabelas 3 e 4 , respectivamente.

Antes de realizar a comparação de médias, foi feita uma análise multivariada das variáveis ganho diário de peso e consumo diário de ração. Na Tabela 5 são apresentadas as probabilidades (valores de $\mathrm{P}$ ) obtidas nessa análise. Pode-se concluir que existe diferença entre os tratamentos para essas variáveis.

Mesmo após o desdobramento dos graus de liberdade do fator nível de extrato vegetal na dieta em seus componentes individuais de regressão, pelos polinômios ortogonais, não foi observada $(\mathrm{P}>0,05)$ qualquer resposta no ganho diário de peso e no consumo diário de ração dos leitões.

Durante os períodos de 1 a 14 e 1 a 35 dias de experimentação, os resultados de peso vivo, consumo diário de ração e ganho diário de peso no tratamento antimicrobiano foram melhores $(\mathrm{P}<0,05)$ que os obtidos no tratamento controle e com os diferentes níveis de extratos vegetais na dieta. A diferença no desempenho entre os animais dos tratamentos antimicrobiano e controle demonstra o alto grau de desafio ao qual os animais foram submetidos, pois quanto maior o desafio, maior o efeito dos antimicrobianos sobre o desempenho dos animais (Menten, 2002).

A conversão alimentar dos leitões não foi influenciada $(\mathrm{P}>0,05)$ pelos tratamentos em nenhum dos períodos considerados, embora os melhores resultados numéricos tenham sido observados para os animais do tratamento antimicrobiano e do tratamento com o maior nível de inclusão de extrato vegetal.

Tabela 3 - Médias de peso vivo aos 14 dias (P14, kg), consumo diário de ração (CDR, kg/dia), ganho diário de peso (GDP, kg/dia) e conversão alimentar (CA) de leitões para o período de 1 a 14 dias de experimentação

Table 3 - $\quad$ Average body weight at 14 days (BW14, $\mathrm{kg})$, average daily feed intake (DFl, $\mathrm{kg} /$ day), average daily weight gain (GDP, $\mathrm{kg} /$ day) and feed conversion (F/G) of weanling pigs from 1 to 14 days of experiment

\begin{tabular}{|c|c|c|c|c|}
\hline \multicolumn{2}{|c|}{$\begin{array}{l}\text { Tratamento }{ }^{1} \\
\text { Treatment }\end{array}$} & \multicolumn{2}{|c|}{$\begin{array}{l}\text { Variável } \\
\text { Variable }\end{array}$} & \multirow[b]{2}{*}{$\mathrm{CA}$} \\
\hline & $\mathrm{P} 14^{2}(\mathrm{~kg})$ & $\mathrm{CDR}^{2}(\mathrm{~kg} / \mathrm{dia})$ & $\mathrm{GDP}^{2}(\mathrm{~kg} / \mathrm{dia})$ & \\
\hline & & & & \\
\hline $\mathrm{C}$ & 7,642 & 0,263 & 0,169 & 2,23 \\
\hline A & 8,469 & 0,316 & 0,218 & 1,98 \\
\hline $\mathrm{Ea}$ & 7,548 & 0,261 & 0,151 & 2,59 \\
\hline $\mathrm{Eb}$ & 7,535 & 0,239 & 0,151 & 2,41 \\
\hline Ec & 8,007 & 0,282 & 0,185 & 2,25 \\
\hline $\operatorname{Pr}>F$ & 0,0005 & 0,0004 & 0,0004 & 0,1565 \\
\hline $\mathrm{CV}^{3}(\%)$ & 7,11 & 14,21 & 22,83 & 25,73 \\
\hline
\end{tabular}

${ }^{1} \mathrm{C}=$ controle (control); $\mathrm{A}=$ antimicrobiano (antimicrobial); Ea, Eb e Ec $=700$ $1.400,2.100 \mathrm{ppm}$ de extrato vegetal (herbal extract), respectivamente.

2 Contrastes significativos: controle $x$ antimicrobiano e antimicrobiano $x$ extratos.

2 Significantly different contrasts: control $x$ antimicrobial and antimicrobial $x$ herbal extract.

3 Coeficiente de variação (Coefficient of variation).

Tabela 4 - Médias de peso vivo aos 35 dias (P35, kg), consumo diário de ração (CDR, kg/dia), ganho diário de peso (GDP, kg/dia) e conversão alimentar (CA) no período de 1 a 35 dias de experimentação

Table 4 - $\quad$ Average body weight at 35 days $(P 35, \mathrm{~kg})$, average daily feed intake (CFI, kg/day), average daily weight gain ( $A W G, \mathrm{~kg} /$ day) and feed conversion (F/G) of weanling pigs from 1 to 35 days of experiment

\begin{tabular}{|c|c|c|c|c|}
\hline \multirow[t]{3}{*}{$\begin{array}{l}\text { Tratamen } \\
\text { Treatment }\end{array}$} & \multicolumn{4}{|c|}{$\begin{array}{l}\text { Variável } \\
\text { Variable }\end{array}$} \\
\hline & $\mathrm{P} 35^{2}(\mathrm{~kg})$ & $\mathrm{CDR}^{2}(\mathrm{~kg} / \mathrm{dia})$ & $\mathrm{GDP}^{2}(\mathrm{~kg} / \mathrm{dia})$ & $\mathrm{CA}$ \\
\hline & $B W 14(\mathrm{~kg})$ & DFI (kg/day) & $D W G \quad(\mathrm{~kg} /$ day $)$ & $F / G$ \\
\hline $\mathrm{C}$ & 17,576 & 0,597 & 0,347 & 1,74 \\
\hline A & 19,488 & 0,674 & 0,402 & 1,71 \\
\hline $\mathrm{Ea}$ & 17,175 & 0,590 & 0,335 & 1,80 \\
\hline $\mathrm{Eb}$ & 16,228 & 0,538 & 0,309 & 1,76 \\
\hline Ec & 17,635 & 0,607 & 0,349 & 1,75 \\
\hline $\operatorname{Pr}>F$ & 0,0068 & 0,0010 & 0,0065 & 0,8734 \\
\hline $\mathrm{CV}^{3}(\%)$ & 11,55 & 11,54 & 16,65 & 11,67 \\
\hline
\end{tabular}

${ }^{1} \mathrm{C}=$ controle (control); $\mathrm{A}=$ antimicrobiano (antimicrobial); Ea, Eb e Ec $=700$, $1400,2100 \mathrm{ppm}$ de extrato vegetal (herbal extract), respectivamente.

${ }^{2}$ Contrastes significativos: controle $\mathrm{x}$ antimicrobiano e antimicrobiano $\mathrm{x}$ extratos.

2 Significantly different contrasts: control $x$ antimicrobial and antimicrobial $x$ herbal extract.

${ }^{3}$ Coeficiente de variação (Coefficient of variation). 
Apesar de as diferenças entre tratamentos não terem sido significativas, os resultados de desempenho foram melhores à medida que se aumentou o nível de extratos vegetais na dieta. $\mathrm{O}$ tratamento com $2.100 \mathrm{ppm}$ de extrato vegetal (Ec) apresentou resultados intermediários de desempenho entre os tratamentos antimicrobiano e controle, principalmente no período de 1 a 14 dias de experimentação.

O melhor desempenho dos animais que receberam antimicrobianos na dieta pode ser atribuído ao seu efeito sobre a microbiota intestinal, atuando como agentes bactericidas ou bacteriostáticos, causando efeitos interativos com a fisiologia do animal (Muramatsu et al., 1994), como a economia de nutrientes, o efeito protetor contra a produção de toxinas no trato gastrintestinal, o efeito no controle de doenças subclínicas e o efeito metabólico (Menten, 1995).

Um dos modos de ação atribuído aos extratos vegetais na dieta pode ser o efeito antimicrobiano. Em um estudo in vitro realizado por Dorman \& Deans (2000), os óleos essenciais de cravo, tomilho e orégano apresentaram pronunciado efeito antimicrobiano sobre determinados patógenos. O efeito antimicrobiano está relacionado, principalmente, à alteração da permeabilidade e integridade da membrana celular bacteriana (Lambert et al., 2001). Existe uma relação entre a estrutura química dos compostos ativos presentes no extrato vegetal e seu efeito antimicrobiano (Farag et al., 1989), sendo que, geralmente, esse efeito pode ser atribuído à presença de compostos fenólicos (Dorman $\&$ Deans, 2000). Alguns extratos vegetais apresentam alto poder antimicrobiano sobre diversos patógenos em estudos in vitro. Entretanto, o nível de inclusão para que esse efeito seja observado é, geralmente, elevado, um dos motivos pelo qual o tratamento com o maior nível de inclusão de extratos vegetais $(2.100 \mathrm{ppm})$ apresentou melhores resultados de desempenho. Outro fator, discutido anteriormente, está relacionado à melhora na digestibilidade aparente da matéria seca (Tabela 4). O aumento na digestibilidade de um nutriente contribui para o melhor aproveitamento do alimento pelo animal, resultando em melhor desempenho.
O modo de ação dos extratos vegetais em experimento in vivo não foi totalmente esclarecido e comprovado. Alguns trabalhos relatam resposta positiva do uso de extratos vegetais na dieta e outros não. Jamroz \& Kamel (2002) observaram que frangos alimentados com uma combinação de extratos vegetais apresentaram maior ganho de peso ( 625 vs $578 \mathrm{~g} /$ dia) e melhor conversão alimentar (1,44 vs 1,56$)$ que os animais do tratamento controle. De acordo com os autores, a suplementação com extratos vegetais aumentou a digestibilidade dos nutrientes e favoreceu o equilíbrio da microbiota, diminuindo o potencial de adesão de patógenos ao epitélio intestinal. Em experimentos com leitões, a inclusão de $0,75 \%$ de uma combinação de extratos vegetais na dieta promoveu maior ganho de peso em relação aos animais controle ( $26 \mathrm{vs}-5 \mathrm{~g} / \mathrm{dia}$ ) na primeira semana pós-desmame, sendo que nos outros períodos não foram encontradas diferenças significativas (Jeaurond et al., 2002). Para suínos em fase de crescimento e terminação, o efeito benéfico da utilização de extrato(s) vegetal(is) na dieta geralmente está relacionado à melhora na conversão alimentar. Confirmando essa hipótese, Lima et al. (2001) e Thaler et al. (2004) obtiveram respostas positivas sobre a eficiência alimentar de suínos nas fases de crescimento e terminação recebendo suplementação com uma combinação de óleos essenciais e/ou ácidos orgânicos na dieta. Porém, nem sempre são encontradas diferenças significativas para o ganho de peso e o consumo de ração (Thaler et al., 2004). Da mesma forma, Kwon et al. (2004), utilizando um extrato vegetal à base de Artemisia capillaris, encontraram melhoras significativas na conversão alimentar à medida que aumentaram de 0,02 para $0,06 \%$ o nível de inclusão desse extrato na dieta dos animais. Uma possível explicação para essa melhora da conversão alimentar pode estar relacionada ao fato de que animais adultos apresentam o sistema digestório mais desenvolvido (quanto à produção enzimática e à morfo-histologia intestinal) e que o efeito de estimulação da secreção pancreática, supostamente exercido pelos extratos vegetais (Sambaiah \& Srinivasan, 1991; Platel \& Srinivasan, 1996; Wang \& Bourne, 1998), é mais pronunciado para essa categoria animal.

Tabela 5 - Valores de P obtidos nos testes estatísticos da análise multivariada

Table 5 - $\quad P$ value obtained by different tests in the multivariate analysis

Combinação de variável ${ }^{1}$

Combination of variable
Teste estatístico - Valores de P

Statistical test $-P$ value

\begin{tabular}{|c|c|c|c|c|c|}
\hline & Wilks' Lambda & Pillai's Trace & Hotelling-Lawley Trace & Roy's & Greatest Root \\
\hline GDP e CDR (1-14 dias) & 0,0037 & 0,0066 & 0,0028 & & 0,0003 \\
\hline GDP e CDR (1-35 dias) & 0,0322 & 0,0442 & 0,0262 & & 0,0028 \\
\hline
\end{tabular}

\footnotetext{
1 Ganho diário de peso e consumo diário de ração no período de 1 a 14 e 1 a 35 dias de experimentação.
}

${ }^{1}$ Daily weight gain and feed intake during 1 to 14 and 1 to 35 days of experiment. 
Em outros experimentos com frangos (Botsoglou et al., 2002b; Cross et al., 2003; Demir et al., 2003; Lee et al., 2003a, 2003b; Hernández et al., 2004), não foi possível observar diferença estatística no desempenho dos animais que receberam suplementação com diferentes tipos, concentrações e combinações de extratos vegetais na dieta. De acordo com Lee et al. (2003a), a ausência de efeito no desempenho dos animais pode estar relacionada à composição da dieta basal utilizada e/ou às condições ambientais a que foram submetidos os animais. Dietas altamente digestíveis limitam o desenvolvimento de bactérias no trato intestinal, pela redução de substrato disponível ao crescimento bacteriano, diminuindo o potencial antimicrobiano dos extratos vegetais. O mesmo pode acontecer se os animais tiverem sido alojados em instalações com baixo desafio imunológico e rigoroso controle sanitário.

Em virtude das variações nas respostas encontradas na literatura, ainda não foi possível esclarecer o modo de ação dos extratos vegetais nas diferentes espécies animais. São necessários mais estudos para comprovar sua eficácia e determinar a melhor relação entre os diferentes tipos de extratos vegetais e suas concentrações na dieta para maximizar o desempenho dos animais e torná-los uma alternativa viável ao uso de antimicrobianos como promotores do crescimento.

Na Tabela 6 são descritas as médias dos pesos relativos (em porcentagem do peso vivo) dos órgãos digestórios e não digestórios, assim como do comprimento, do comprimento relativo e da relação peso:comprimento do intestino delgado, em função dos tratamentos.

Foram encontradas diferenças significativas entre os tratamentos apenas para o peso relativo do trato gastrintestinal total e do intestino delgado vazio. As demais variáveis não sofreram efeitos significativos dos tratamentos. Os animais do tratamento com antimicrobiano apresentaram menor peso relativo do trato gastrintestinal total $(\mathrm{P}<0,05)$ que os do tratamento controle ou com diferentes níveis de extratos vegetais. Quanto ao peso relativo do intestino delgado vazio, o tratamento controle apresentou valores intermediários entre os demais tratamentos, sendo inferior $(\mathrm{P}<0,05)$ ao tratamento com extratos vegetais e superior $(\mathrm{P}<0,07)$ àquele com antimicrobianos.

Os resultados encontrados estão de acordo com a literatura. Um dos modos de ação dos agentes antimicrobianos está relacionado à redução na quantidade de microrganismos (produtores de toxinas) aderidos ao epitélio intestinal e à conseqüente redução da espessura da parede intestinal (Anderson et al., 1999), o que proporciona economia de nutrientes pelo animal para a manutenção dos tecidos do trato gastrintestinal (Lima, 1999), favorecendo seu desempenho.

Neste estudo, os animais que receberam extratos vegetais na dieta apresentaram, numericamente, maior peso relativo do pâncreas. Este resultado também foi encontrado em outros trabalhos nos quais foram encontradas diferenças numéricas significativas (Lewis et al., 2004) ou não (Utiyama, 2004; Lee et al., 2003a) do peso relativo do pâncreas nos animais que receberam extratos vegetais em relação aos do tratamento controle. O aumento do pâncreas pode ser indicativo de um estímulo da secreção pancreática e do aumento da atividade enzimática. Confirmando essa hipótese, Lee et al. (2003a) observaram aumento da atividade da amilase intestinal em relação ao tratamento controle (114 vs 111 unidades/g conteúdo intestinal) para frangos aos 21 dias de idade recebendo uma combinação de extratos vegetais (100 ppm) na dieta, contudo, aos 40 dias de idade esse efeito não se manteve e o tratamento que proporcionou melhor resultado foi o tratamento à base de timol (princípio ativo do tomilho), sendo observado aumento de $26 \%$ na atividade da tripsina intestinal. Considerando esses resultados, infere-se que a sensibilidade das enzimas endógenas aos extratos vegetais pode ser modificada de acordo com a idade dos animais (Lee et al., 2003a).

O peso relativo do fígado é outro dado que deve ser considerado. Os animais que receberam extratos vegetais na dieta apresentaram, numericamente, peso relativo do fígado maior que o do tratamento controle ( 2,67 vs 2,90, 2,85 e $2,95 \%$, sendo controle vs Ea, Eb e Ec, respectivamente). Embora não seja possível esclarecer o motivo desse aumento, vale ressaltar que, em outro experimento, frangos aos 21 dias de idade recebendo $100 \mathrm{ppm}$ de timol na dieta também apresentaram aumento $(\mathrm{P}<0,05)$ no peso relativo do fígado em relação ao tratamento controle ( 2,59 vs $2,30 \mathrm{~g} / 100 \mathrm{~g}$ PV) (Lee et al., 2003a).

$\mathrm{Na}$ Tabela 7 constam as médias de altura das vilosidades (AV), de profundidade das criptas (PC), da relação altura de vilosidade/profundidade de cripta (AV/PC) do duodeno, jejuno e íleo, em função dos tratamentos.

Houve diferenças entre os tratamentos $(\mathrm{P}<0,05)$ apenas para as variáveis altura de vilosidade do íleo e relação altura de vilosidade:profundidade de cripta do íleo. A maior altura de vilosidade foi obtida com o tratamento antimicrobiano em relação aos tratamentos com extratos vegetais. Para a relação altura de vilosidade:profundidade de cripta do íleo, os tratamentos com extratos vegetais diferiram $(\mathrm{P}<0,05)$ tanto do tratamento com antimicrobiano quanto do trata- 
Tabela 6 - Médias dos pesos relativos (\% do peso vivo) dos órgãos, do comprimento, do comprimento relativo e da relação peso:comprimento do intestino delgado, de acordo com os tratamentos

Table 6 - Average relative weight (\% of live weight) of organs, small intestine length, small intestine relative length, and weight:small intestine length ratio according to treatments

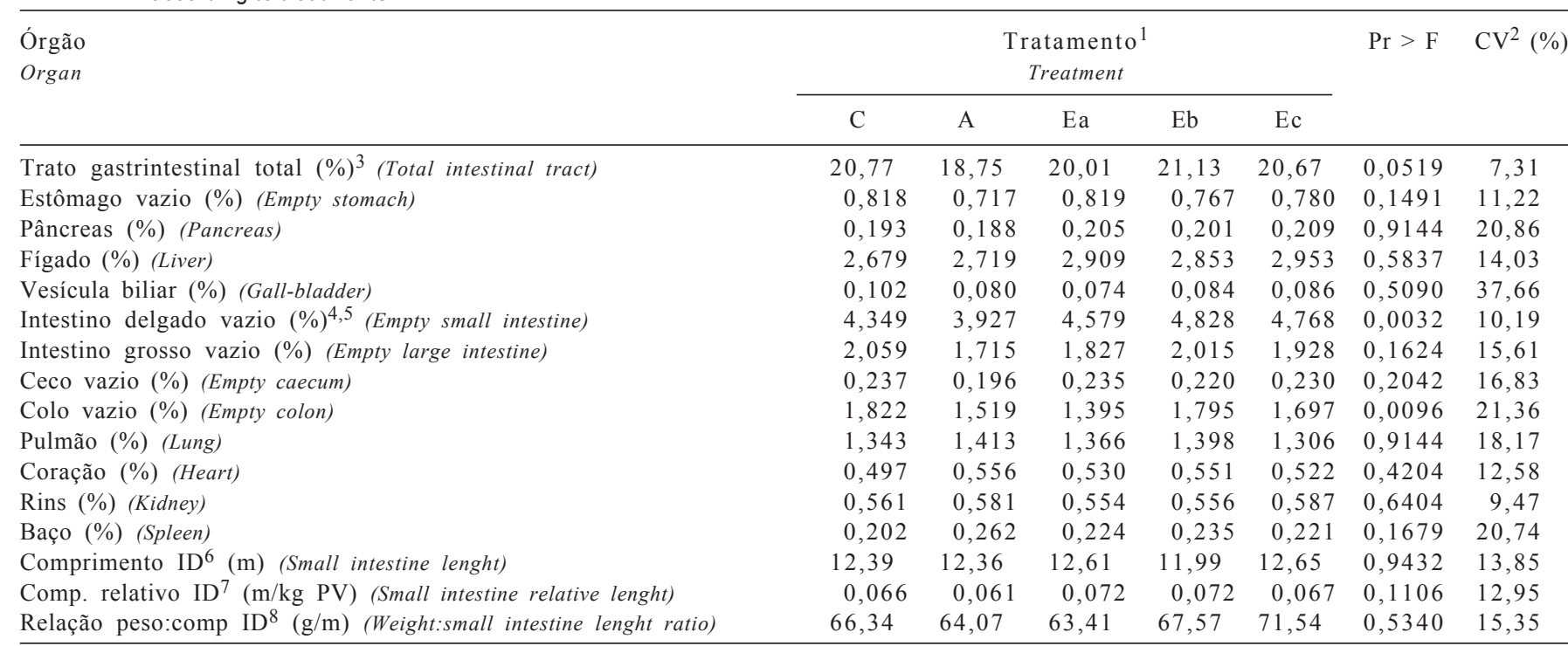

$1 \mathrm{C}=$ controle (control); $\mathrm{A}=$ antimicrobiano (antimicrobial); Ea, Eb e Ec =700, 1.400, 2.100 ppm de extrato vegetal (herbal extract), respectivamente.

2 Coeficiente de variação (coefficient of variation).

3 Contrastes significativos: controle $\mathrm{x}$ antimicrobiano e antimicrobiano $\mathrm{x}$ extratos.

4 Contrastes significativos: controle $x$ antimicrobiano, controle $x$ extratos e antimicrobiano $x$ extratos.

${ }^{5}$ Efeito linear significativo para os níveis crescentes de extrato na dieta, em que $\hat{Y}=0,150 x+4,255\left(R^{2}=0,81\right)$.

${ }_{7}^{6}$ Comprimento do intestino delgado.

${ }^{7}$ Comprimento relativo do intestino delgado ( $\mathrm{m} / \mathrm{kg}$ de peso vivo no momento do abate).

8 Relação peso:comprimento do intestino delgado.

${ }^{3}$ Significantly different contrasts: control $x$ antimicrobial and antimicrobial $x$ herbal extract.

4 Significantly different contrasts: control x antimicrobial, control $x$ herbal extracts and antimicrobial $x$ herbal extract.

${ }^{5}$ Linear effect for increasing levels of herbal extract.

${ }^{6}$ Small intestine lenght.

${ }^{7}$ Small intestine relative lenght ( $\mathrm{m} / \mathrm{kg}$ of body weight at slaughter).

${ }^{8}$ Weight:small intestine lenght ratio.

mento controle, apresentando menores valores que em ambos os tratamentos.

No período pós-desmame, há, normalmente, atrofia das vilosidades em decorrência do aumento na taxa de descamação epitelial por consequência do início do consumo de ração sólida, do baixo consumo de ração, de toxinas bacterianas e da adesão de bactérias aos enterócitos (Cera et al., 1988). O aumento na descamação resulta em incremento da profundidade da cripta (Tucci, 2003) para assegurar a adequada taxa de renovação celular e garantir a reposição das perdas de células da região apical dos vilos (Pluske et al., 1997). Assim, quanto maior a altura das vilosidades e menor a profundidade das criptas, melhor a absorção de nutrientes e menores as perdas energéticas com o turnover celular.

Pelos resultados, não foi possível observar efeito significativo da utilização dos extratos vegetais sobre a histologia do epitélio intestinal. Contudo, no jejuno, os maiores níveis de inclusão de extrato vegetal resultaram em maior altura de vilosidade e menor profundidade de cripta que os demais tratamentos. Esses resultados indicam que, possivelmente, haja uma ação específica do extrato vegetal sobre determinada área do intestino delgado. Existem outros trabalhos na literatura onde são observadas melhorias na histologia do epitélio intestinal com a utilização de extratos vegetais na dieta. Demir et al. (2003) observaram redução $(\mathrm{P}<0,05)$ na profundidade de cripta de frangos que receberam tomilho na dieta em relação ao tratamento controle (157,8 vs 181,3 mm). Em leitões, embora os resultados também não tenham mostrado diferenças significativas, o tratamento com extratos vegetais (500 ppm) também trouxe efeitos benéficos ao epitélio intestinal, aumentando a altura das vilosidades e a relação altura de vilosidade:profundidade de cripta tanto no duodeno quanto no jejuno (Utiyama, 2004).

Em virtude do reduzido número de trabalhos com suínos, avaliando os efeitos de extratos vegetais sobre a histologia do epitélio intestinal, não é possível esclarecer e comprovar o efeito dos extratos vegetais sobre essa variável. 
Tabela 7 - Médias de altura das vilosidades (AV), profundidade das criptas (PC), relação altura de vilosidade:profundidade de cripta (AV/PC) do duodeno, jejuno e íleo, de acordo com os tratamentos

Table 7 - Average villus height (AV), crypt detht (PC), and villus height/crypt depth ratio (AV/PC) of duodenum, jejunum and ileum according to treatments

\begin{tabular}{|c|c|c|c|c|c|c|c|}
\hline \multirow[t]{2}{*}{$\begin{array}{l}\text { Órgão } \\
\text { Organ }\end{array}$} & \multicolumn{5}{|c|}{$\begin{array}{l}\text { Tratamento } \\
\text { Treatment }\end{array}$} & \multirow[t]{2}{*}{$\operatorname{Pr}>F$} & \multirow[t]{2}{*}{$\mathrm{CV}^{2}(\%)$} \\
\hline & $\mathrm{C}$ & A & $\mathrm{Ea}$ & $\mathrm{Eb}$ & Ec & & \\
\hline \multicolumn{8}{|c|}{ Duodeno (duodenum) } \\
\hline $\mathrm{AV}(\mathrm{mm})$ & 266 & 238 & 261 & 245 & 249 & 0,9771 & 27,54 \\
\hline $\mathrm{PC}(\mathrm{mm})$ & 263 & 230 & 242 & 267 & 271 & 0,7731 & 20,95 \\
\hline $\mathrm{AV} / \mathrm{PC}$ & 1,10 & 1,13 & 1,20 & 1,06 & 1,08 & 0,9738 & 39,10 \\
\hline \multicolumn{8}{|c|}{ Jejuno (jejunum) } \\
\hline $\mathrm{AV}(\mathrm{mm})$ & 188 & 191 & 199 & 219 & 298 & 0,3850 & 39,10 \\
\hline $\mathrm{PC}(\mathrm{mm})$ & 278 & 277 & 311 & 228 & 246 & 0,1828 & 17,55 \\
\hline $\mathrm{AV} / \mathrm{PC}$ & 0,70 & 0,76 & 0,75 & 1,11 & 1,36 & 0,1665 & 44,16 \\
\hline \multicolumn{8}{|l|}{ Íleo (ileum) } \\
\hline $\mathrm{AV}(\mathrm{mm})^{3}$ & 252 & 291 & 206 & 234 & 191 & 0,0413 & 17,98 \\
\hline $\mathrm{PC}(\mathrm{mm})^{4,5}$ & 215 & 217 & 233 & 213 & 230 & 0,7086 & 11,24 \\
\hline $\mathrm{AV} / \mathrm{PC}$ & 1,26 & 1,44 & 0,89 & 1,19 & 0,84 & 0,0079 & 18,77 \\
\hline
\end{tabular}

${ }^{1} \mathrm{C}=$ controle (control); $\mathrm{A}=$ antimicrobiano (antimicrobial); Ea, Eb e Ec = 700, 1.400, 2.100 ppm de extrato vegetal (herbal extract), respectivamente.

2 Coeficiente de variação (coefficient of variation).

3 Contraste significativo: antimicrobiano $x$ extratos.

4 Contrastes significativos: controle $x$ extratos e antimicrobiano $x$ extratos.

5 Efeito cúbico $(P<0,05)$ para os níveis crescentes de extrato na dieta, em que $\hat{Y}=-0,21 x^{3}+1,65 x^{2}-3,79 x+3,62\left(R^{2}=1,00\right)$

${ }^{3}$ Significantly different contrasts: antimicrobial $x$ herbal extract.

${ }^{4}$ Significantly different contrasts: control $x$ herbal extract and antimicrobial $x$ herbal extract.

${ }^{5}$ Cubic effect for increasing levels of herbal extract.

\section{Conclusões}

Os agentes antimicrobianos melhoraram o peso vivo, o consumo diário de ração e o ganho diário de peso em todos períodos analisados. Entre os níveis de inclusão dos extratos vegetais, o maior foi o que proporcionou melhores resultados de desempenho. A utilização de extratos vegetais na dieta de leitões recém-desmamados não alterou a morfometria dos órgãos e a histologia do epitélio intestinal, mas aumentou a digestibilidade aparente da matéria seca.

\section{Literatura Citada}

ANDERSON, D.B.; McCRACKEN, V.J.; AMINOV, R.I. et al. Gut microbiology and growth-promoting antibiotics in swine. Pig News Information, v.20, p.115N-122N, 1999.

BOTSOGLOU, N.A.; FLOROU-PANERI, P.; CHRISTAKI, E. et al. Effect of dietary oregano essential oil on performance of chickens ando $\mathrm{n}$ iron-induced lipid oxidation of breast, thigh and abdominal fat tissues. British Poultry Science, v.43, p.223-230, 2002 .

BRUGALI, I. Alimentação alternativa: a utilização de fitoterápicos ou nutracêuticos como moduladores da imunidade e desempenho animal. In: SIMPÓSIO SOBRE MANEJO E NUTRIÇÃO DE AVES E SUÍNOS, 2003, Campinas. Anais... Campinas: Colégio Brasileiro de Nutrição Animal, 2003. p.167-182.

CERA, K.R.; MAHAN, D.C.; CROSS, R.F. et al. Effect of age, weaning and postweaning diet on small intestinal growth and jejunal morphology in young swine. Journal of Animal Science, v.66, p. $574-584,1988$.

CROSS, D.E.; SVOBODA, K.; McDEVITT, R.M. et al. The performance of chickens fed diets with and without thyme oil and enzymes. British Poultry Science, v.44, p.S18-S19, 2003.
DEMIR, E.; SARICA, S.; ÖZCAN, M.A. et al. The use of natural feed additives as alternative for an antibiotic growth promotres in broiler diets. British Poultry Science, v.44, p.S44-S45, 2003.

DORMAN, H.J.D.; DEANS, S.G. Antimicrobial agents from plants: antibacterial activity of plant volatile oil. Journal of Applied Microbiology, v.83, p.308-316, 2000.

FARAG, R.S.; DAW, Z.Y.; HEWEDI, F.M. et al. Antimicrobial activity of some egyptian spice essential oils. Journal of Food Protection, v.52, n.9, p.665-667, 1989.

HERNANDEZ, F.; MADRID, J.; GARCIA, V. et al. Inlfuence of two plant extracts on broilers performance, digestibility, and digestive organ size. Poultry Science, v.83, p.169-174, 2004.

JAMROZ, D.; KAMEL, C. Plant extracts enhance broiler performance. Journal of Animal Science. v.80, p.41, 2002 (suppl. 1).

JEAUROUND, E.; SCHUMANN, B.; CLUNIES, M. et al. Suplementation of diets with herbal extracts enhances growth performance in newly-weaned piglets. Journal of Animal Science, v.80, p.394, 2002 (suppl. 1).

KAMEL, C. A novel look at a classic approach of plant extracts. Feed Mix, p.19-24, 2000. Número especial.

KWON, S.; MIN, B.J.; LEE, W.B. et al. Effect of dietary natural herb extract (Biomate) supplementation on growth performance, IGF-1 and carcass characteristics in growingfinishing pigs. Journal of Animal Science, v.82, supp1. 1, p. 177, 2004 .

LAMBERT, R.J.W.; SKANDAMIS, P.N.; COOTE, P.J. et al. A study of the minimum inhibitory concentration and mode of action of oregano essential oil, thymol and carvacrol. Journal of Applied Microbiology, v.91, p.453-462, 2001.

LEE, K.W.; EVERTS, H.; KAPPERT, H.J. et al. Effects of dietary essential oil components on growth performance, digestive enzymes and lipid metabolism in female broiler chickens. British Poultry Science, v.44, n.3, p.450-457, 2003a.

LEE, K.W.; EVERTS, H.; KAPPERT, H.J. et al. Dietary carvacrol lowers body weight but improves feed conversion in female broiler chickens. Journal of Applied Poultry Research, v.12, p.394-399, 2003b. 
LEWIS, M.R.; ROSE, S.P.; MACKENZIE, A.M. et al. The effects of dietary herbal extracts for broiler chickens. Journal of Animal Science, v.82, supp1. 1, p.169, 2004.

LIMA, G.J.M.M.; VIOLA, E.S.; NONES, K. et al. Avaliação de dietas com BMD (bacitracina metileno disalicilato) e salinomicina sobre o desempenho de suínos em crescimento e terminação. In: CONGRESSO BRASILEIRO DE VETERINÁRIOS ESPECIALISTAS EM SUÍNOS, 9., 1999, Belo Horizonte. Anais... Belo Horizonte: ABRAVES, 1999. p.464-465.

LIMA, G.J.M.M.; RUTZ, F.; BORGES, S.A. et al. Efeito da adição de um composto de ervas naturais como promotor de crescimento de dietas de suínos em crescimento e terminação. In: CONGRESSO BRASILEIRO DE VETERINÁRIOS ESPECIALISTAS EM SUÍNOS, 10., 2001, Foz do Iguaçu. Anais... Foz do Iguaçu: ABRAVES, 2001. p.323-324.

MELLOR, S. Herbs and spices promote health and growth. Pig Progress, v. 16, n.4, 2000

MENTEN. J.F.M. Probióticos, prébióticos e aditiovos fitogênicos na nutrição de aves. In: SINPÓSIO SOBRE INGREDIENTES NA ALIMENTAÇÃO ANIMAL, 2., 2002, Campinas. Anais... Campinas: Colégio Brasileiro de Nutrição Animal, 2002. p.251-276.

MENTEN, J.F.M. Eficácia, efeito sinérgico e modo de ação de agentes antimicrobianos como promotores do crescimento de suínos. Piracicaba: Escola Superior de Agricultura "Luiz de Queiroz", 1995. 106p. Tese (Livre Docência) - Escola Superior de Agricultura "Luiz de Queiroz", 1995.

MILTEMBERG, G. Extratos herbais como substitutos de antimicrobianos na alimentação animal. In: SIMPÓSIO SOBRE ADITIVOS ALTERNATIVOS NA NUTRIÇÃO ANIMAL, 2000, Campinas. Anais... Campinas: IAC, 2000. p.87-100

MURAMATSU, T.; NAKAJIMA, S.; OKUMURA, J. Modification of the energy metabolism by preence of the gut microflora in the chiken. British Journal of Nutrition, v.71, p.709$717,1994$.

PLATEL, K.; SRINIVASAN, K. Influence of dietary spices or their active principles on digestive enzymes of small intestinal mucosa in rats. International Journal of Food Sciences and Nutrition, v.47, p.55-59, 1996.
PLUSKE, J.R.; HAMPSON, D.J.; WILLIAMS, J.H. Factors influencing the structure and function of the small intestine in the weaned pig: a review. Livestock Production Science, v.51, p.215-236, 1997.

SAMBAIAH, K.; SRINIVASAN, K. Secretion and composition of bile in rats fed diets containing spices. Journal of Food Science and Technology, v.28, p.35-38, 1991.

STATISTICAL ANALYSIS SYSTEM - SAS. SAS user's guide statistics. Cary: 1996. 955p.

SILVA, E.N. Antibióticos intestinais naturais: bacteriocinas. In: SIMPÓSIO SOBRE ADITIVOS ALTERNATIVOS NA NUTRIÇÃO ANIMAL, 2000, Campinas. Anais... Campinas: Instituto Agronômico de Campinas, 2000. p.15-24

THALER, R.C.; ROPS, B.D.; CHRISTOPHERSON, B.T. et al Efficacy of SUPROL as a growth promotant for grow-finish pigs. Journal of Animal Science, v.82, p.99, 2004 (suppl. 1)

TUCCI, F.M. Efeitos da adição de agentes tróficos na dieta de leitões desmamados sobre a renovação celular da mucosa intestinal, enzimas digestivas e desempenho. Jaboticabal: Universidade Estadual Paulista, 2003. 84p. Tese (Doutorado) Universidade Estadual Paulista, 2003.

UTIYAMA, C.E. Utilização de agentes antimicrobianos, probióticos, prebióticos e extratos vegetais como promotores do crescimento de leitões recémdesmamados. Piracicaba: Escola Superior de Agricultura "Luiz de Queiroz", 2004. 94p. Tese (Doutorado) - Escola Superior de Agricultura "Luiz de Queiroz", 2004

WANG, R.; LI, D.; BOURNE, S. Can 2000 years of herbal medicine history help us solve problems in year 2000?. In: ALLTECH'S ANNUAL SYMPOSIUM, 14., 1998, Nottingham. Proceedings... Nottingham: ALLTECH, 1998. p.168-184. 